\title{
Effect of Copper Content on Compressive Strength and Microstructure of Dental Amalgams
}

\author{
Akram Hasheminezhad, Seyed Mojtaba Zebarjad*, Seyed Abdolkarim Sajjadi, Laleh Rahanjam \\ Department of Metallurgy and Materials Engineering, Engineering Faculty, \\ Ferdowsi University of Mashhad, Mashhad, Iran \\ Email: ${ }^{*}$ Zebarjad@um.ac.ir
}

Received November 18, 2011; revised January 4, 2012; accepted January 10, 2012

\begin{abstract}
The main goal of this research is to investigate the effect of copper on compressive strength of dental amalgam. For this purpose amalgam capsules with two different content of copper were used. Cylindrical samples with diameter to height ratio 1 to 2, were prepared via molding method. To evaluate the role of copper element on compressive strength, compression test was done at different strain rates i.e. $0.02,0.2,0.4$ and $2 \mathrm{~min}^{-1}$. The results and microscopic evaluations showed that an increase in copper content in amalgam caused to eliminate gamma2 phase and leaded to promote compressive strength.
\end{abstract}

Keywords: Amalgam; Copper; Compressive Strength; Microstructure; Gamma2

\section{Introduction}

Dental amalgams constitute almost $75 \%$ of all restorative materials used in dental practice. They are obtained from the combination of mercury and a silver-copper-tin powder [1]. Early dental amalgams (1900-1965) composed of $66 \%-67 \% \mathrm{Ag}, 25 \%-28 \% \mathrm{Sn}, 0 \%-6 \% \mathrm{Cu}$ and $1 \% \mathrm{Zn}$ so called as low copper amalgam. Reaction that occurs is observed below [2]:

$$
\begin{aligned}
& \mathrm{Ag}_{3} \mathrm{Sn}(\gamma)+\mathrm{Hg} \\
& \rightarrow \mathrm{Ag}_{2} \mathrm{Hg}_{3}\left(\gamma_{1}\right)+\mathrm{Sn}_{7-8} \mathrm{Hg}\left(\gamma_{2}\right)+\mathrm{Ag}_{3} \mathrm{Sn} \text { (unreacted) }
\end{aligned}
$$

The reaction products are about $54 \%-56 \% \mathrm{Ag}_{2} \mathrm{Hg}_{3}\left(\gamma_{1}\right)$ phase, $32 \%-35 \% \mathrm{Ag}_{3} \mathrm{Sn}(\gamma)$ phase and $11 \%-13 \%$ $\mathrm{Sn}_{7-8} \mathrm{Hg}\left(\gamma_{2}\right)$ phase. The $\gamma_{2}$ phase is the most corrosion prone phase and its hardness is almost $10 \%$ of that of $\gamma_{1}$ phase [3]. In order to eliminate $\gamma_{2}$ phase, in 1965, the high copper amalgam with $12 \%-30 \%$ copper were produced. They are much more corrosion resistant. In this amalgams copper reacts with tin and $\mathrm{Cu}_{6} \mathrm{Sn}_{5}$ phase is formed instead of $\mathrm{Sn}_{7-8} \mathrm{Hg}[4,5]$. Thus it eliminates $\gamma_{2}$ phase. This reaction is shown below [2].

$$
\begin{aligned}
& \mathrm{Ag}_{3} \mathrm{Sn}(\gamma)+\mathrm{Ag}-\mathrm{Cu}(\text { eutectic })+\mathrm{Hg} \\
& \rightarrow \mathrm{Ag}_{2} \mathrm{Hg}_{3}\left(\gamma_{1}\right)+\mathrm{Cu}_{6} \mathrm{Sn}_{5}(\eta)+\mathrm{Ag}_{3} \mathrm{Sn} \text { (unreacted) } \\
& \quad+\mathrm{Ag}-\mathrm{Cu}(\text { unreacted })
\end{aligned}
$$

Although there are a lot of papers in the field of physiccal and chemical properties of dental amalgam [6-14], only a few consider the mechanical behavior of this material.

*Corresponding author.

\section{Experimental Procedure}

\subsection{Materials}

Two series of alloy powders and mercury were prepared. According to manufacturer claim the type of both alloy powders was lathe-cut and spherical. SEM micrograph and analysis of this powder are shown in Figures $\mathbf{1}$ and $\mathbf{2}$. The details of used materials are summarized in Table $\mathbf{1}$. Just for simplicity the materials were coded. The main goal of this research is to find out the effect of copper on compressive strength of dental amalgams.

\subsection{Sample Preparation}

The alloy powders and mercury were mixed mechanically at different ratio. Table 2 illustrates the mixing condition

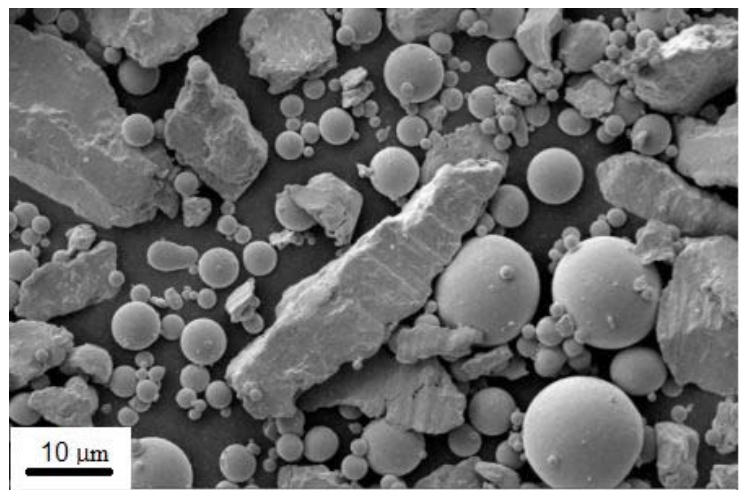

Figure 1. SEM micrograph of admixed high copper amalgam. 

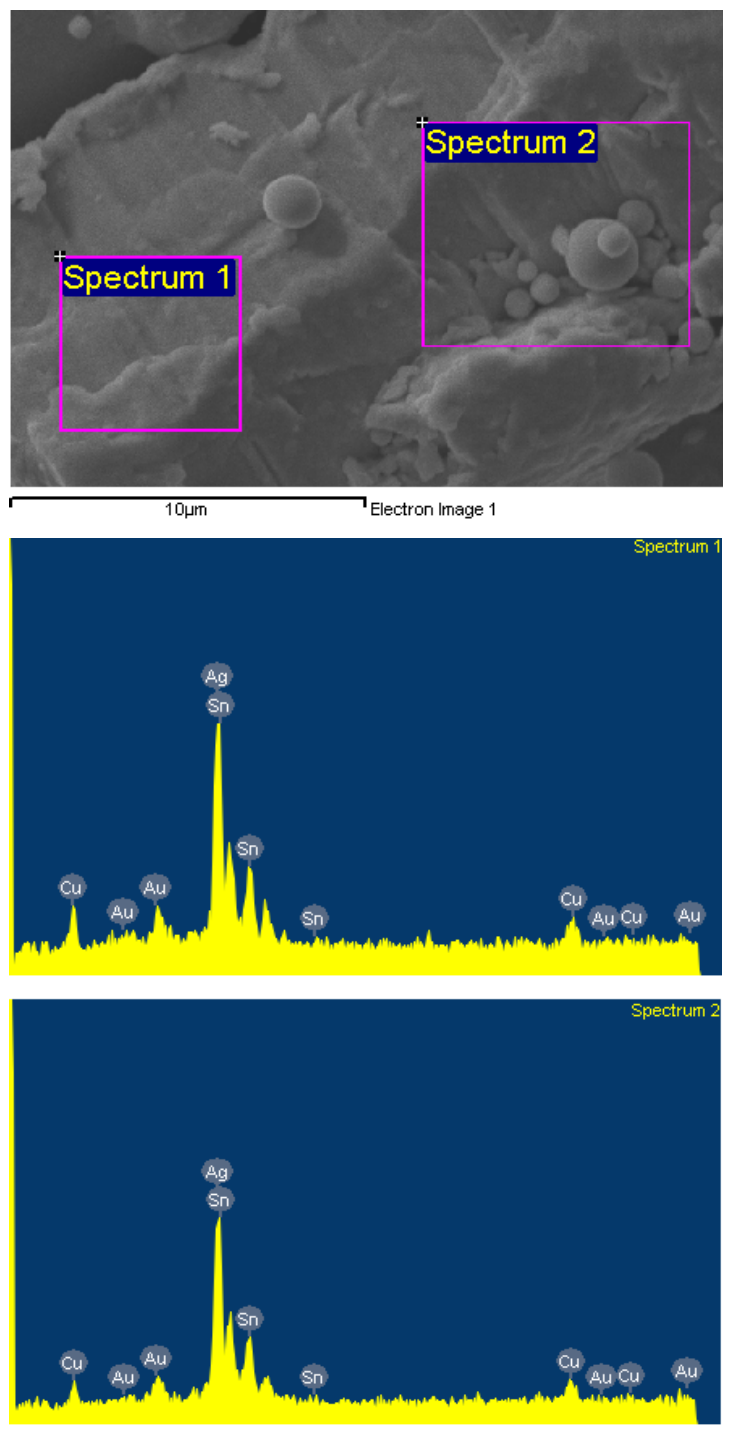

Figure 2. SEM analysis of admixed high copper amalgam.

Table 1. Specification of used alloy powders.

\begin{tabular}{cccccc}
\hline material & $\begin{array}{c}\text { Commercial } \\
\text { name }\end{array}$ & $\begin{array}{c}\text { Percent of } \\
\mathrm{Ag}(\mathrm{wt} \%)\end{array}$ & $\begin{array}{c}\text { Percent of } \\
\mathrm{Sn}(\mathrm{wt} \%)\end{array}$ & $\begin{array}{c}\text { Percent of } \\
\mathrm{Cu}(\mathrm{wt} \%)\end{array}$ & $\begin{array}{c}\text { Percent of } \\
\mathrm{Zn}(\mathrm{wt} \%)\end{array}$ \\
\hline S1 & SDI, permit & 56 & 27.95 & 15.4 & 2 \\
S2 & SDI, gs-80 & 40 & 31.35 & 28.7 & - \\
\hline
\end{tabular}

Table 2. Mixing condition.

\begin{tabular}{cc}
\hline Sample & Per capsule \\
\hline A1 & $400 \mathrm{mgr}$ Alloy, $364 \mathrm{mgr} \mathrm{Hg}$ \\
A2 & $600 \mathrm{mgr}$ Alloy, 552mgr Hg \\
\hline
\end{tabular}

for making amalgam. After mixing and before amalgamation, the standard samples were made using molding method. The heights of the samples were varied from 11 to $13 \mathrm{~mm}$. Mold and prepared specimens are shown in Figure 3.
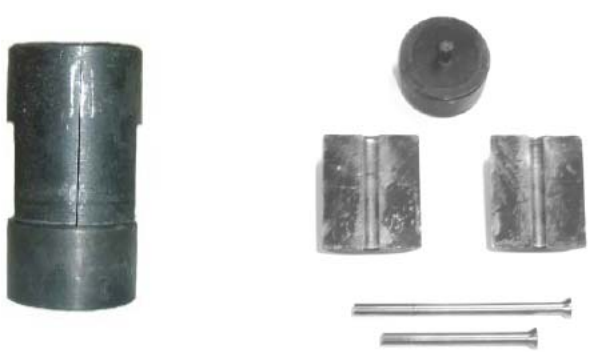

Figure 3. Mold and prepared specimens.

\subsection{Microscopic Evaluation}

To study the role of copper element on amalgam microstructure, the surface of some samples were polished to achieve a surface roughness of about $5 \mu \mathrm{m}$. Then the polished surfaces of the samples were investigated using both optical and SEM microscopes.

\subsection{Mechanical Test}

Compressive test were carried out with a Zwick tensile machine at different strain rates $0.02,0.2,0.4$ and $2 \mathrm{~min}^{-1}$. Microhardness measurement carried out with a Vickers indentor under a load of $1 \mathrm{Kg}$ and $500 \mathrm{~g}$.

\section{Results and Discussion}

The microstructure of the A2 sample shows a continuous $\mathrm{Ag}-\mathrm{Hg}$ matrix that simultaneously is formed with $\mathrm{Cu}_{6} \mathrm{Sn}_{5}$ phase and embeds $\eta$ phase and $\mathrm{Sn}-\mathrm{Ag}$ alloy particles. Also Ag-Cu eutectic particles are surrounded with $\eta$ phase. In this sample in addition to $\eta$ layers, a small amount of $\eta$ crystals are found (Figures 4-6).

Figures 7-9 show microstructures of A1 samples. Comparison of both microstructure (i.e. A1 \& A2) shows gamma2 phase amount decreases and eta phase amount increases as copper content add.

Since gamma1 phase plays like a barrier against crack propagate, thus fracture of amalgam alloy should be under control of copper content. Figures $\mathbf{1 0}$ and 11 illustrate the dependency of fracture stress of amalgam alloy on copper content. However residual $\mathrm{Ag}_{3} \mathrm{Sn}$ particles in amalgam increase, amalgam strength is also increased. This is important because the matrix phase is the weaker and more corrosion prone than the residual alloy particles gamma phase is stable in mouth periphery. Also pure gammal phase is stable but existence gammal in amalgam have a small quantity tin that is the most corrosion prone phase in mouth, so gamma2 phase have low corrosion resistant and low compressive strength and can cause to crack propagation in amalgam. Furthermore interface between gamma phase and matrix is very magnitude. If interface strength is not coefficient can be caused crack nucleation and growth. Also $\mathrm{Cu}_{6} \mathrm{Sn}_{5}$ phase increases the strength of high copper amalgams. In amalgam with lower 


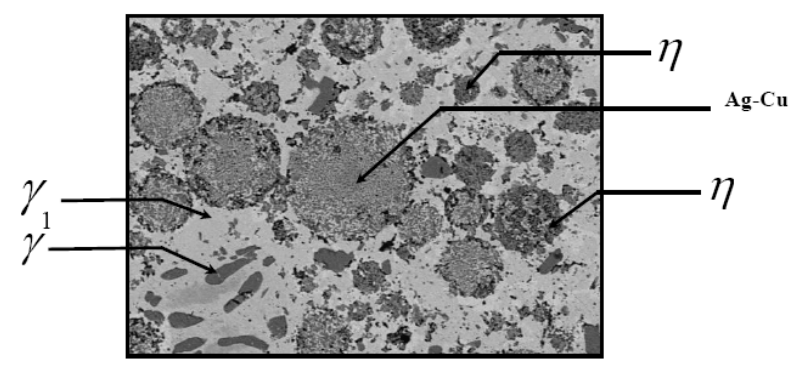

Figure 4. The microstructure of the A2 sample.

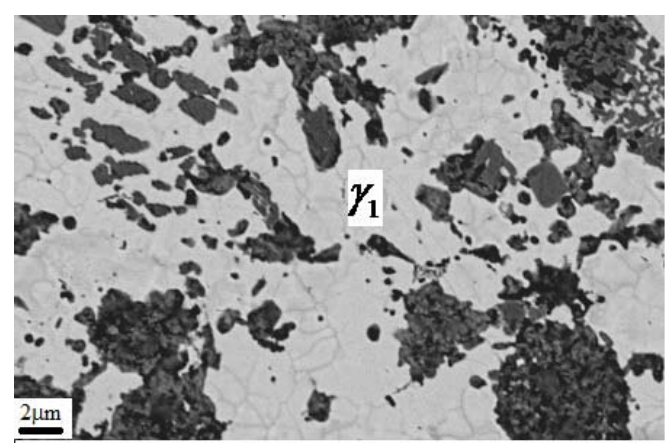

Figure 5. SEM micrograph of A2 sample.
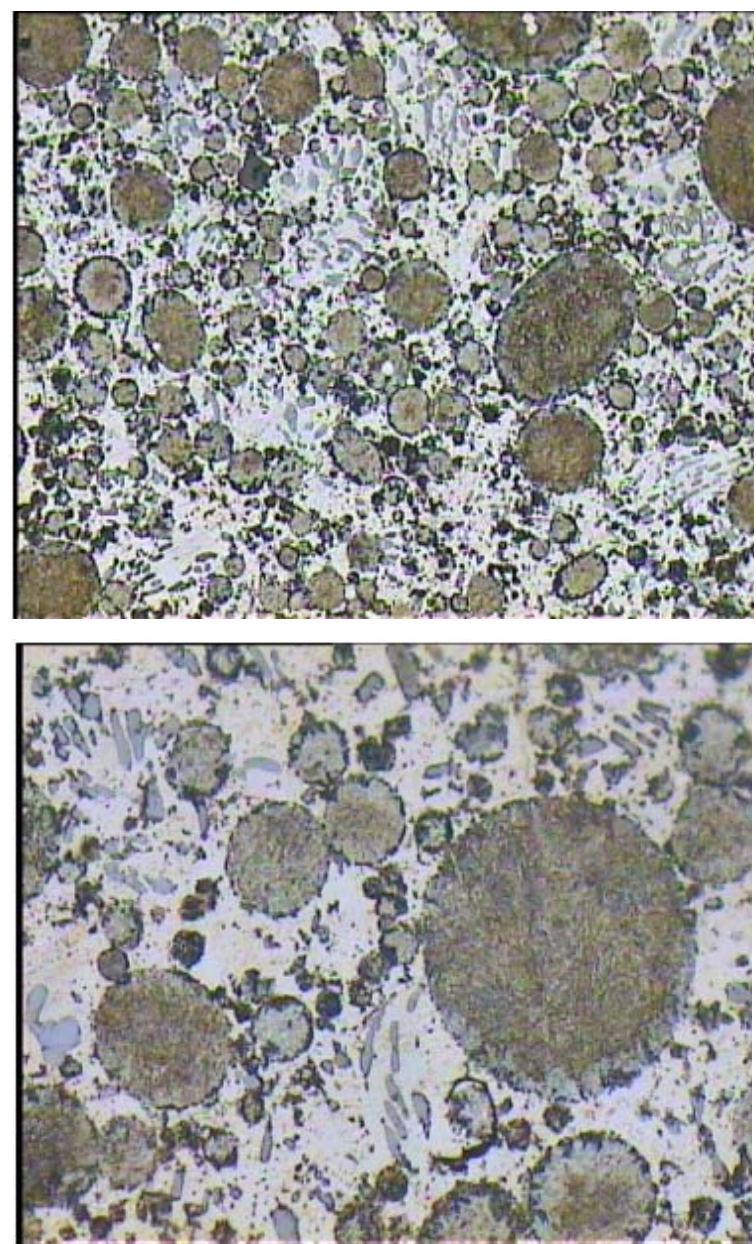

Figure 6. Optical micrographs of A2 sample.

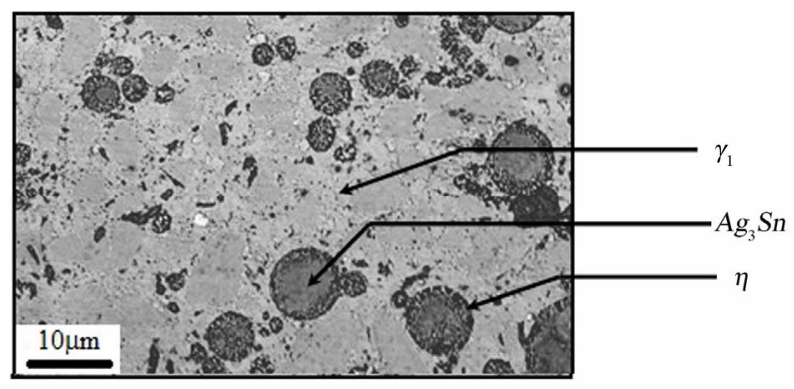

Figure 7. SEM micrograph of A1 sample.

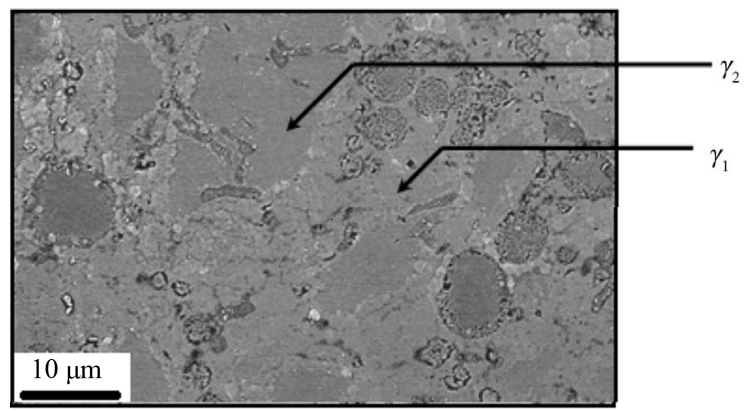

Figure 8. Gama1 and gama2 appear in A1 sample.
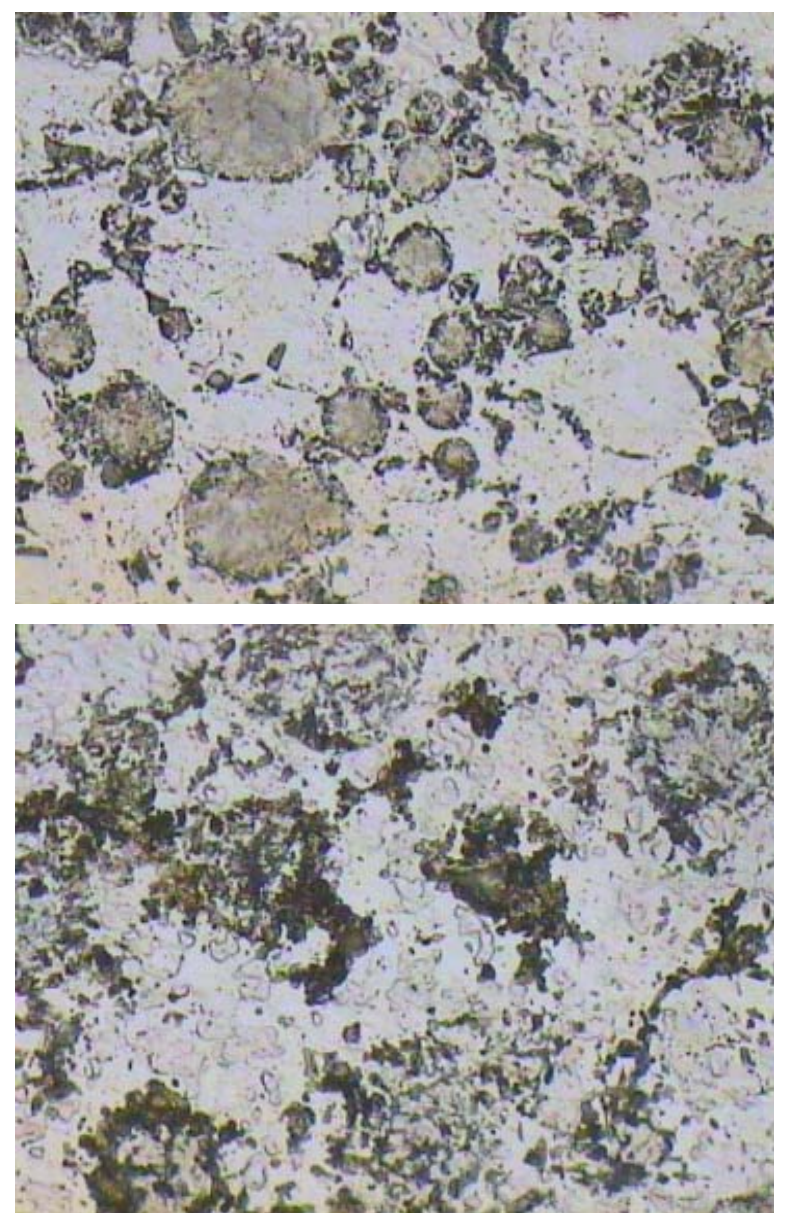

Figure 9. Optical micrograph taken from the polished surface of A1 sample. 

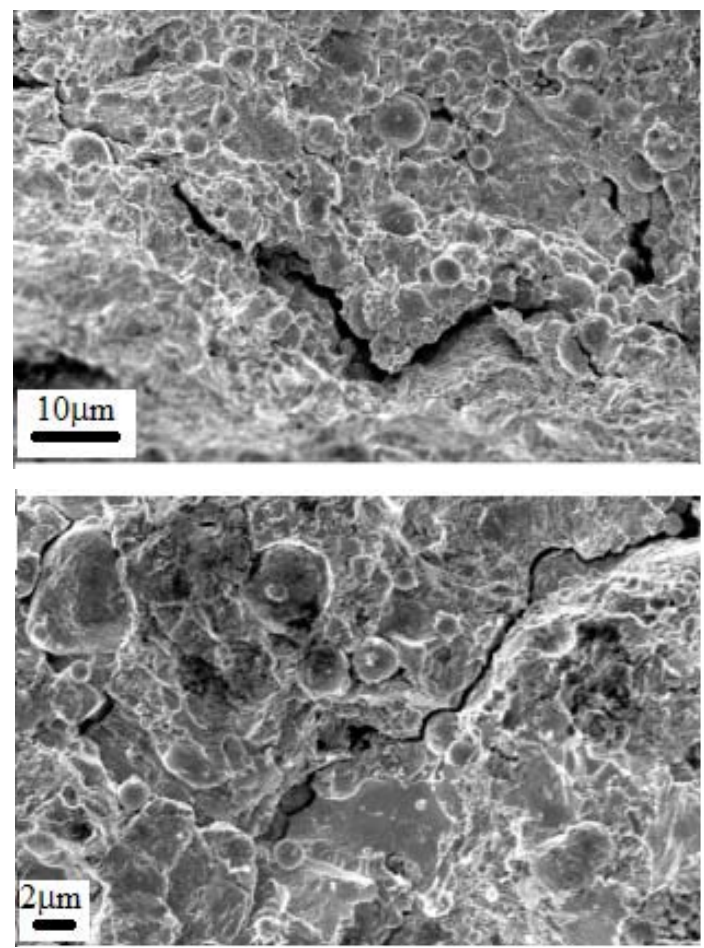

Figure 10. SEM micrographs taken from the fracture surface of A1 sample.

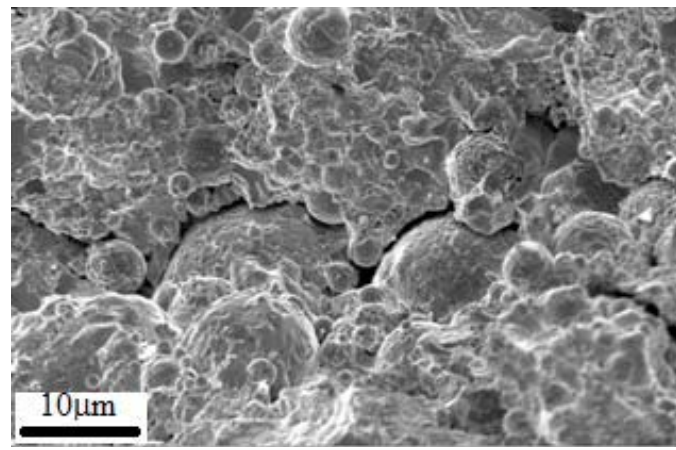

Figure 11. SEM micrograph of fracture surface of A2 sample.

copper content (A1), alloy powder consists of more lathe-cut particles than spherical particles. So particles total area and also required mercury content for diffusion in particles increase, on the other hand mercury diffusion causes to contraction, therefore contraction for this amalgam decreases. On the other hand $\gamma_{1}$ and $\gamma_{2}$ phases formation result in expansion. These changes neutralize one another in a good amalgam, but usually its expansion is more than contraction. It induces porosity that is a location for stress concentration and decreases compressive force, thus spherical particles not only harden rather stronger in compression than lathecut particles and Figure 12 Confirms this claim.

Whereas compressive strength is a function of strain rate, samples were tested in $0.02,0.2,0.4$ and $2 \mathrm{~min}^{-1}$ strain rates. The required force versus strain rate for $\mathrm{A} 1$ and A2 samples are shown in Figure 13. It can be observed a decrease in force with increasing strain rate for both samples. Also can be seen that A1 sample has less fracture force than A2 sample. Deviation of displacement and elasticity modulus versus strain rate as a function of copper content in turn are shown in Figures 14 and 15. Results of microhardness measurements (Table 3 ) are in agreement with results of compression test.

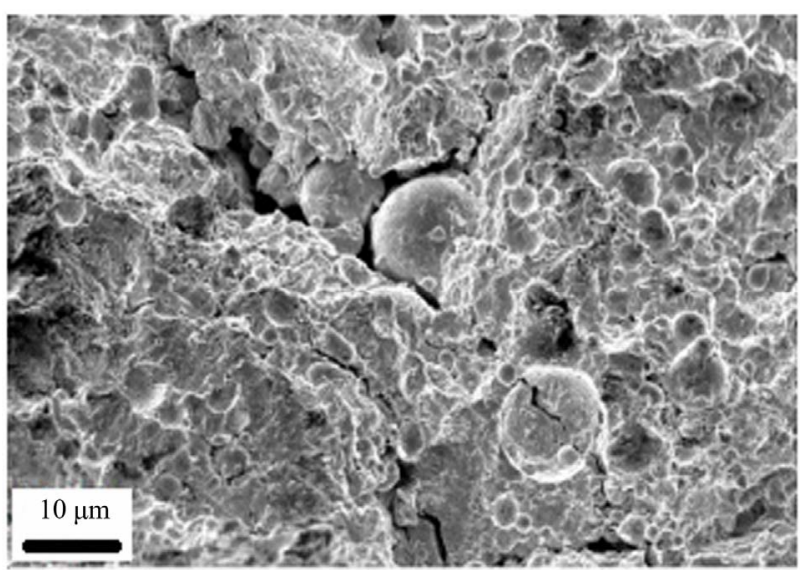

Figure 12. Crack propagation in A1 sample.

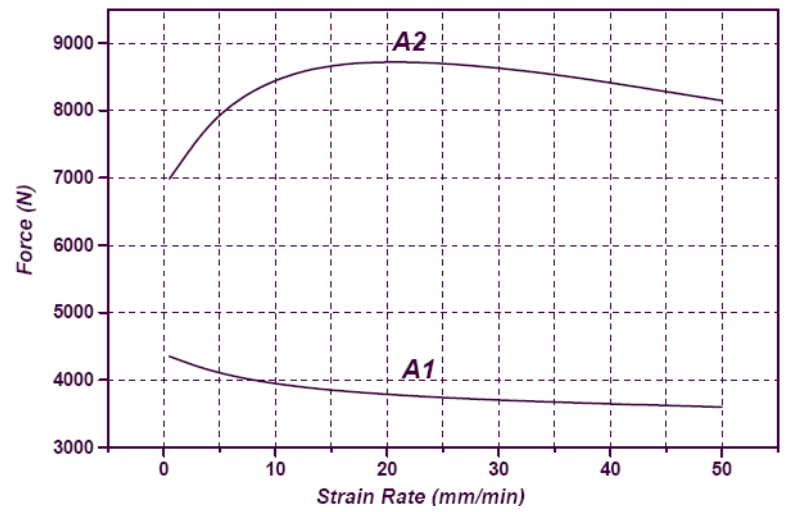

Figure 13. Variation of force versus strain rate of A2 and A1 sample.

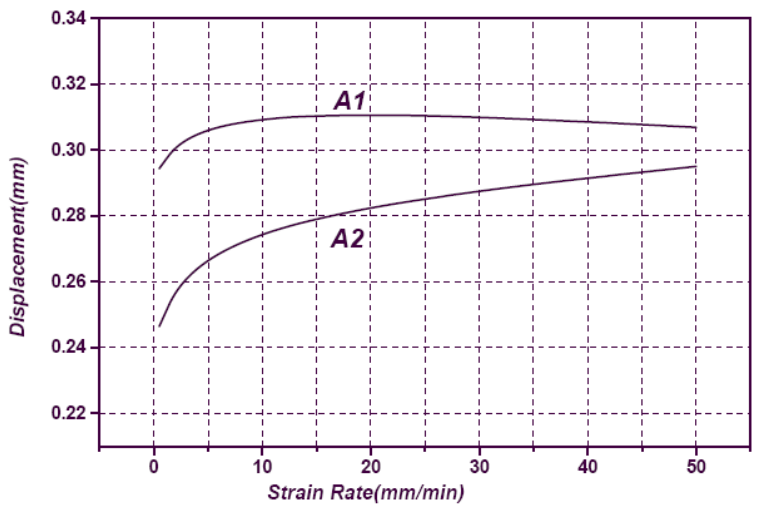

Figure 14. Variation of displacement versus strain rate as a function of $\mathrm{Cu}$. 


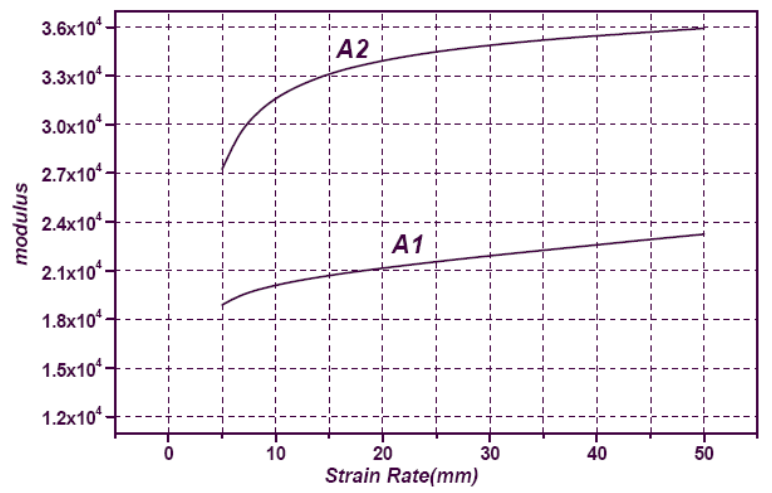

Figure 15. Variation of modulus versus strain rate as a function of copper.

Table 3. Dependence of microhardness of amalgams as a function of copper content.

\begin{tabular}{ccc}
\hline sample & $\left(\mathrm{HV}_{1}\right)$ & $\left(\mathrm{HV}_{0.5}\right)$ \\
\hline $\mathrm{A} 2$ & 190.75 & 188.5 \\
$\mathrm{~A} 2$ & 177.3 & 178 \\
$\mathrm{~A} 1$ & 149.7 & 168 \\
$\mathrm{~A} 1$ & 139.47 & 123 \\
$\mathrm{~A} 1$ & 110.7 & 121 \\
\hline
\end{tabular}

\section{Conclusions}

The results of study may be summarized as follows:

1) Addition of copper content to dental amalgam alloy causes an increase in compressive strength and hardness.

2) Required fracture stress for amalgam with specific $\mathrm{Cu}$ weight percent $(\mathrm{wt} \% \mathrm{Cu})$ is raised when strain rate increases.

3) Increasing copper content in amalgam alloy powders cause to deform the powder particles from lathe-cut to spherical.

\section{REFERENCES}

[1] C. Bracho-Troconis, P. Colon, J.-D. Bartout and Y. Bienvenu, "Influence of Thermal Treatments on $\mathrm{Ag} \mathrm{Sn} \mathrm{Cu}$ Powders in Order to Reduce Mercury Contents in Dental Amalgam," Journal of Materials Science: Materials in Medicine, Vol. 11, No. 1, 2000, pp. 1-9. doi:10.1023/A:1008979532764

[2] R. G. Craig and J. M. Powers, "Restorative Dental Materials," Mosby, St. Louis, 2002.
[3] S. Tsutsumi, M. Nakamura, J. L. Ferracane, T. L. Schiller, T. Hanawa and T. Okabe, "Thermal Analysis of Amalgams," Dental Materials, Vol. 4, No. 5, 1988, pp. 307311. doi:10.1016/S0109-5641(88)80027-7

[4] T. Okabe and R. J. Mitchell, "Setting Reactions in Dental Amalgam. Part 2. The Kinetics of Amalgamation," Critical Reviews in Oral Biology \& Medicine, Vol. 7, No. 1, 1996, pp. 23-35. doi:10.1177/10454411960070010201

[5] T. Okabe, R. J. Mitchell and C. W. Fairhurst, "A Study of High Copper Amalgams. IV. Formation of $\eta \mathrm{Cu}-\mathrm{Sn}$ $\left(\mathrm{Cu}_{6} \mathrm{Sn}_{5}\right)$ Crystals in a High Copper Dispersant Amalgam Matrix," Journal of Dental Research, Vol. 58, No. 3, 1979, pp. 1087-1092. doi:10.1177/00220345790580031001

[6] L. D. Zardiackas and S. C. Bayne, "Fatigue Characterization of Nine Dental Amalgam," Biomaterials, Vol. 6, No. 1, 1985, pp. 49-54.

[7] Y. Uçar and W. A. Brantley, "Biocompatibility of Dental Amalgams," International Journal of Dentistry, 2011, pp. 1-7. doi:10.1155/2011/981595

[8] A. M. Iglesias, S. E. Sorensen, J. M. Carter and R. A. Wilko, "Some Properties of High-Copper Amalgam Alloys Comparing Hand and Mechanical Trituration," The Journal of Prosthetic Dentistry, Vol. 52, No. 2, 1984, pp. 194-198. doi:10.1016/0022-3913(84)90094-5

[9] D. F. Murchison, E. S. Duke, B. K. Norling and T. Okabe, "The Effect of Trituration Time on the Mechanical Properties of Four High-Copper Amalgam Alloys," Dental Materials, Vol. 5, No. 2, 198, pp. 74-76.

[10] D. B. Mahler and J. D. Adey, "Microprobe Analysis of a High Cu Amalgam Alloy," Journal of Dental Research, Vol. 56, No. 4, 1977, pp. 379-384. doi: $10.1177 / 00220345770560040501$

[11] L. D. Zardiackas and L. Anderson Jr., "Crack Propagation in Conventional and High Copper Dental Amalgam as a Function of Strain Rate," Biomaterials, Vol. 7, No. 4, 1986, pp. 259-62. doi:10.1016/0142-9612(86)90046-3

[12] L. Wang, P. Henrique P. D'Alpino, L. G. Lopes and J. C. Pereira, "Mechanical Properties of Dental Restorative Materials," Journal of Applied Oral Science, Vol. 11 No. 3, 2003. doi:10.1590/S1678-77572003000300002

[13] K.-J. M. Söderholm, “An X-Ray Diffractometric Investi- gation of the $\mathrm{Sn}-\mathrm{Hg}$ Binary System within the $0 \%$ 40\% Hg," Journal of Dental Research, Vol. 66, 1987, pp. 712- 715 .

[14] D. B. Mahler, "The High-Copper Dental Amalgam Alloys," Journal of Dental Research, Vol. 76, No. 1, 1997, pp. 537-541. doi:10.1177/00220345970760010301 